\title{
A study of the time course of egg retention activity in the rabbit oviduct
}

\author{
C. V. Gómez and H. B. Croxatto \\ Laboratorio de Endocrinología Instituto de Ciencias Biológicas, Universidad Catolica de Chile, \\ Casilla 114-D, Santiago, Chile
}

\begin{abstract}
Summary. Changes in egg retention activity of the oviduct were assessed during the first 5 days after HCG-induced ovulation in rabbits. Dextran microspheres were used as ovum surrogates. They were injected into the peritoneal cavity at $0,10,32,41,50$, 64,72 and $80 \mathrm{~h}$ following HCG. The distribution of ova and surrogates in the genital tract was assessed $24 \mathrm{~h}$ following surrogate injection in all groups and at $8 \mathrm{~h}$ following surrogate injection in animals injected $50 \mathrm{~h}$ after HCG. The distribution of microspheres injected up to $50 \mathrm{~h}$ after HCG was similar to that of eggs. Surrogates were not retained at the ampullary-isthmic junction (AIJ) shortly after passage of ova through this region. Moreover, spheres injected $38 \mathrm{~h}$ after ovulation reached the eggs at the proximal isthmus in $8 \mathrm{~h}$ or less. Surrogates injected at $64 \mathrm{~h}$ following HCG or later were retained at the $\mathrm{AIJ}$, indicating resumption of retaining activity at this level. It is suggested that egg passage through the AIJ is associated with a temporary reduction of the retaining activity lasting for approximately $16 \mathrm{~h}$. Retaining activity at the AIJ is regained before eggs pass from the proximal isthmus into the uterus.
\end{abstract}

\section{Introduction}

In rabbits, as in other mammals investigated, eggs are retained for several hours close to the region of the ampullary-isthmic junction (AIJ) (Alden, 1942; Greenwald, 1961 ; Humphrey, 1968; Pauerstein, Anderson, Chatkoff \& Hodgson, 1974). The mechanisms responsible for this retention have not been elucidated. However, because inert microspheres are also retained for a similar period (Harper, Bennett, Boursnell \& Rowson, 1960; Croxatto, Vogel \& Vásquez, 1973; Pauerstein, Hodgson, Young, Chatkoff \& Eddy, 1975), it is possible that retention is not dependent on the biological properties of ova but on the interaction of their physical properties with the activity of the oviduct.

It has not been established whether passage of eggs is associated with the disappearance of the retaining mechanisms or whether the retention period represents additional time required for the eggs to pass through a region of higher resistance. The former possibility implies a probable regional and reversible change in the biological and mechanical activities of the oviduct, allowing eggs to move forward. If this is true, donor eggs or inert particles should not experience a retention period if transferred to the oviduct around the time that the native eggs pass through the AIJ.

The purpose of the present study was to determine whether or not passage through the AIJ is associated with a decreased activity of the retaining mechanism and, if so, to assess the time course and reversibility of this change. Time-related variations in the retaining activity were inferred from the distribution of ovum surrogates after their introduction into the peritoneal cavity of rabbits before, during and at various intervals after ovulation.

\section{Materials and Methods}

Female rabbits of mixed breeds weighing more than $3 \mathrm{~kg}$ were kept in individual cages and were injected i.v. with 100 i.u. HCG (Pregnyl: Organon, Oss). This injection was given to induce pseudopregnancy and thereby ensure good development of the genital tract. Between 3 and 8 weeks later, all animals were injected i.v. again with 100 i.u. HCG to induce ovulation. 
Between 0 and $80 \mathrm{~h}$ after the ovulating injection of $\mathrm{HCG}$, all animals received, as ovum surrogates, an intraperitoneal injection of microspheres. According to the time interval between the ovulatory stimulus and the injection of microspheres, the animals were divided into 9 groups of 5-7 rabbits each. Rabbits in Groups 1, 2, 3, 4, 5, 6, 7 and 8 received the injection of surrogates at 0, 10, 32, 41, $50,64,72$ and $80 \mathrm{~h}$, respectively, after HCG and were killed $24 \mathrm{~h}$ later. Group-9 animals received the injection of spheres $50 \mathrm{~h}$ after HCG and were killed $8 \mathrm{~h}$ later.

Microspheres were obtained by sifting Sephadex G-100 (Pharmacia, Sweden) through a set of sieves (A. H. Thomas, Philadelphia). Those retained by sieve openings of $50 \mu \mathrm{m}$ were washed and suspended in Tyrode solution to a concentration of $50,000 / \mathrm{ml}$. The mean diameter of these spheres after autoclaving the suspension was $163 \pm 10 \mu \mathrm{m}$ (S.D.). Each rabbit was injected with $2 \mathrm{ml}$ of the suspension.

All animals were killed by a blow on the neck. The genital tract was removed free of surrounding tissues and divided into five segments corresponding to: (1) distal third of the oviduct; (2) middle third; (3) proximal third; (4) uterine horns; and (5) vagina. Segments 1,2 and 3 were flushed with $2 \mathrm{ml}$ Tyrode solution and Segments 4 and 5 with $10 \mathrm{ml}$. The flushings were collected in embryologic culture dishes and examined at a magnification of $\times 250$ with a dissecting microscope to count ova and microspheres. Spheres recovered from vagina never exceeded $4 \%$ of the total recovered from each animal and half of them were assigned to each side of the tract. The percentage distribution of ova or microspheres in the five segments was calculated for each side separately, taking the total number recovered from each side as $100 \%$. Thus, the right and left sides were treated independently and are subsequently referred to as tracts. Tracts corresponding to a non-ovulating side or containing less than 30 spheres were excluded from the results.

Because the AIJ is located in the most proximal region of the middle third of the oviduct, it was considered that eggs and microspheres present in Segments 1 and 2 had not passed through the AIJ. When more than $50 \%$ of ova and microspheres were found in Segments 1 and 2, it was considered that the retention mechanisms at the AIJ had not disappeared, up to the time of autopsy. When more than $50 \%$ of ova and microspheres were found in Segments 3, 4 and 5, it was considered that the retaining mechanisms had disappeared before autopsy. And when more than $50 \%$ of ova were found in Segments 3, 4 and 5 and spheres were found in Segments 1 and 2, it was considered that the retaining mechanisms had reappeared after the passage of ova and before the injection of ovum surrogates.

To find out whether the number of microspheres had any influence upon their transport, their percentage distribution in tracts (from animals in Groups 1,5 and 8 ) with $>1000$ and $<100$ was compared. Ruptured follicles were counted in each ovary to assess the rate of egg recovery from the genital tract.

\section{Results}

The mean number of rupture points per ovary was 4.85 ; egg recovery from the genital tract was $93 \%$ up to $34 \mathrm{~h}$ following HCG and decreased progressively thereafter to reach $57 \%$ at $104 \mathrm{~h}$ after the hormone injection. The number of spheres recovered per tract varied widely between and within groups. The mean for Groups 1 to 8 ranged between 164 and 946 and the range for individual tracts

Table 1. The effect on their distribution of the percentage microspheres taken up by various segments (see text) of the rabbit genital tract

\begin{tabular}{|c|c|c|c|c|c|c|c|}
\hline \multirow[b]{2}{*}{ Group } & \multirow[b]{2}{*}{ No. of tracts } & \multirow{2}{*}{$\begin{array}{l}\text { Mean no. } \\
\text { of spheres }\end{array}$} & \multicolumn{5}{|c|}{ Segments } \\
\hline & & & 1 & 2 & 3 & 4 & 5 \\
\hline \multirow[t]{2}{*}{1} & 2 & 1228 & 0.8 & $98 \cdot 5$ & 0.7 & $0 \cdot 0$ & $0 \cdot 0$ \\
\hline & 3 & 58 & $16 \cdot 4$ & $82 \cdot 2$ & 1.4 & 0.0 & 0.0 \\
\hline \multirow[t]{2}{*}{5} & 4 & 1973 & 0.7 & $17 \cdot 8$ & 64.9 & 16.6 & 0.0 \\
\hline & 2 & 48 & 0.0 & 3.8 & 76.6 & 18.8 & 0.8 \\
\hline \multirow[t]{2}{*}{8} & 2 & 2887 & $27 \cdot 2$ & $72 \cdot 7$ & 0.0 & 0.0 & $0 \cdot 1$ \\
\hline & 4 & 69 & $26 \cdot 8$ & $73 \cdot 2$ & 0.0 & 0.0 & 0.0 \\
\hline
\end{tabular}



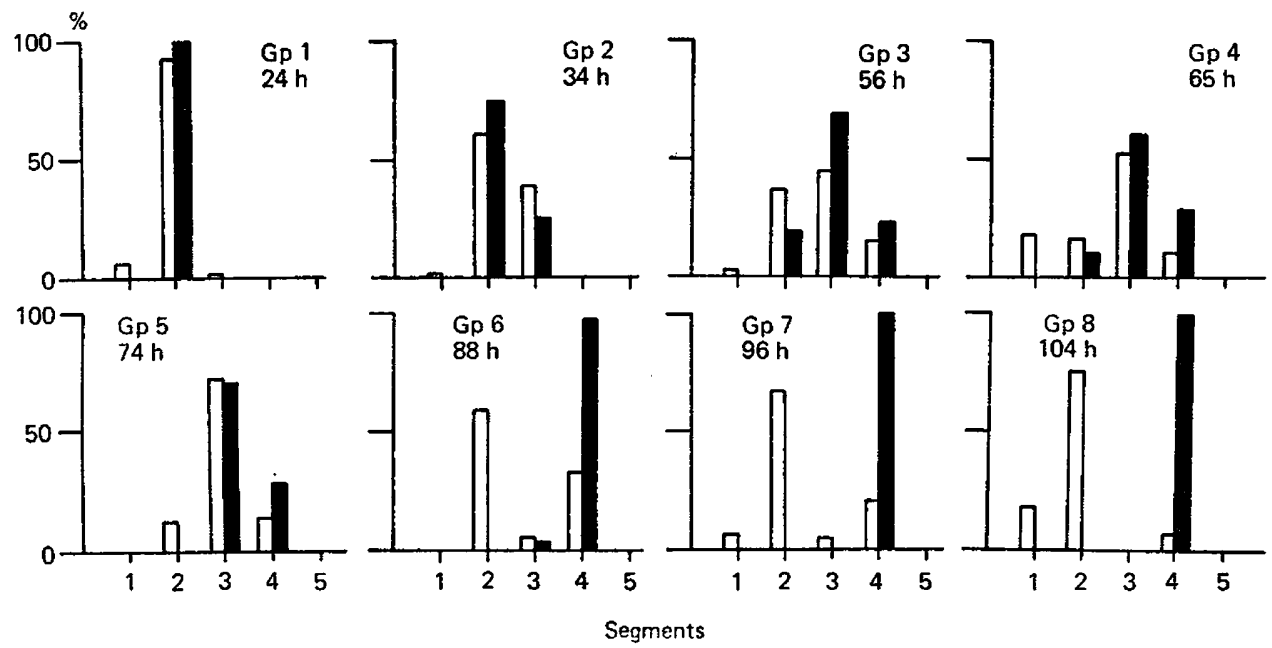

Text-fig. 1. Distribution of eggs and spheres in the genital tract of rabbits at various times after HCG and $24 \mathrm{~h}$ after injection of spheres. Time of autopsy after HCG injection is indicated for each group. Solid bars represent the percentage of eggs in each segment (see text), and open bars the percentage of spheres.

was 31 to 3315. The total number of spheres taken up showed no correlation with the time of injection.

As shown in Table 1, the distribution of microspheres in tracts with low or high numbers of spheres was essentially similar.

The distribution of eggs and surrogates in Groups 1-8 is shown in Text-fig. 1. Injection of microspheres up to $50 \mathrm{~h}$ after HCG (Groups 1-5) resulted $24 \mathrm{~h}$ later in a distribution closely resembling that of eggs. However, while 45 out of 46 eggs were recovered from the uterus in Group $6,60 \%$ of the surrogates were retained in the middle third of the oviduct. This percentage became larger as the time interval between injection of HCG and injection of microspheres increased.

Depending on the distribution of surrogates, each tract was classified as having the retaining mechanisms at the AIJ present or absent. The proportion of tracts with the mechanism present was $100 \%$ for Group 1, 75\% for Group 2, 33\% for Group 3, $25 \%$ for Group 4, $0 \%$ for Group 5, 57\% for Group 6, $73 \%$ for Group 7 and $89 \%$ for Group 8.

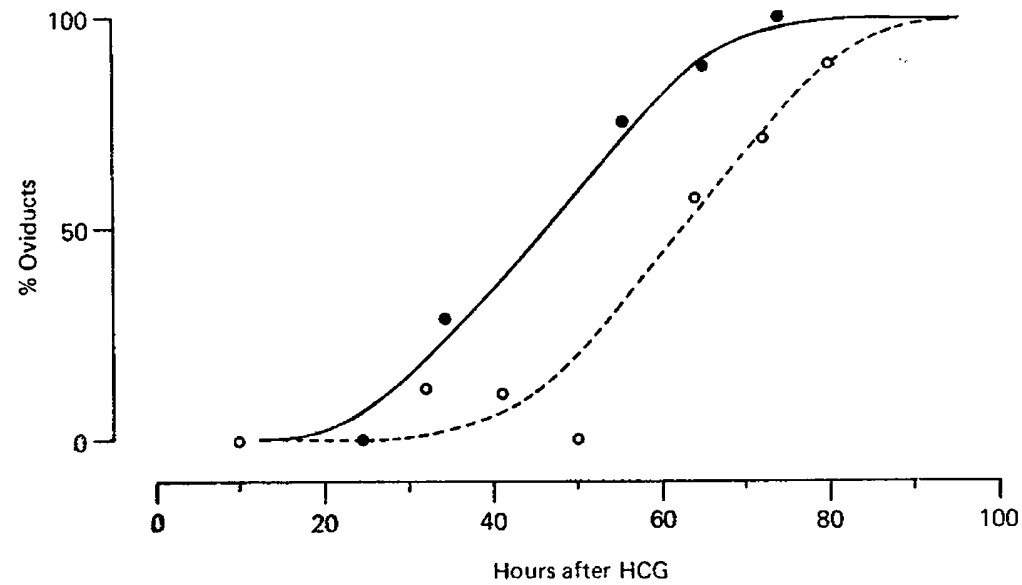

Text-fig. 2. Time course of the disappearance (-) and reappearance (----) of egg retaining mechanisms at the AIJ in the rabbit oviduct after injection of HCG. Dots (๑) indicate the $\%$ of oviducts in which retaining mechanisms had disappeared at the time of autopsy. Circles $(0)$ indicate the $\%$ of oviducts in which retaining mechanisms had reappeared at the time of injection of ovum surrogates. 


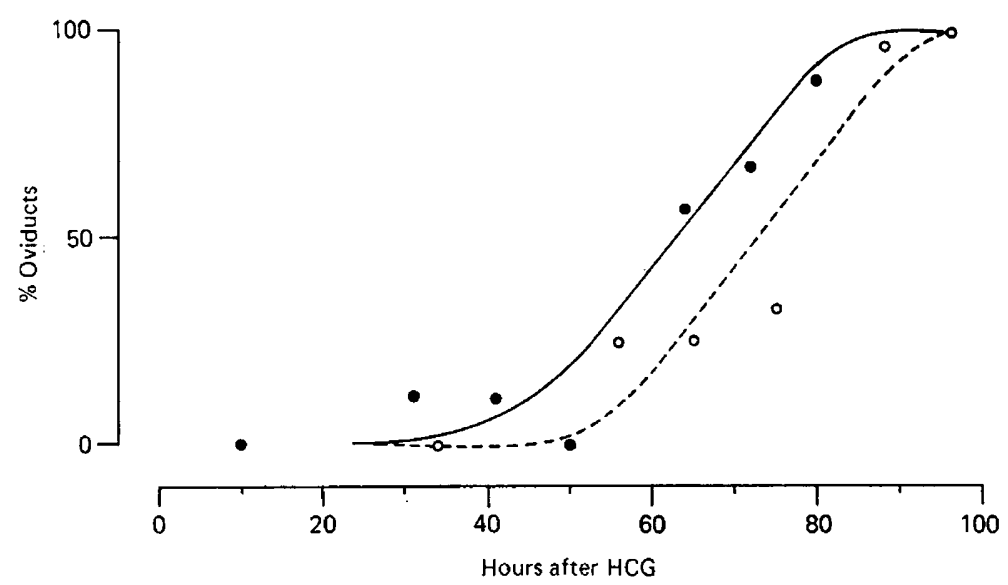

Text-fig. 3. Time relationship between the reappearance of retaining mechanisms (-) at the AIJ and the passage of eggs into the uterus (----) of rabbits. Dots (e) indicate the \% of oviducts in which retaining mechanisms had reappeared at the time of injection of spheres. Circles $(0)$ indicate the $\%$ of tracts in which more than $50 \%$ of the eggs were recovered from the uterus at the time of autopsy.

The proportions of tracts in which the retention mechanism had disappeared at the time of autopsy and in which it had reappeared at the time of injection of surrogates are shown in Text-fig. 2. Two fairly parallel curves obtained were separated by approximately $16 \mathrm{~h}$. The least retention of surrogates occurred when they were injected around $55 \pm 8 \mathrm{~h}$ after HCG.

In 7 tracts from Group 9, the distribution of eggs and spheres was 0 and $4 \%$ respectively in Segment 1, 0 and 24\% in Segment 2, 100 and $69 \%$ in Segment 3, 0 and 3\% in Segment 4 and 0 and $0 \%$ in Segment 5 .

When the proportions of tracts in which the retention mechanisms had reappeared and those with more than $50 \%$ of eggs in the uterus in Groups 1-8 were plotted against time after HCG (Text-fig. 3), it can be seen that reappearance of the retention mechanism preceded the entrance of ova to the uterus by approximately $10 \mathrm{~h}$.

\section{Discussion}

The present results show that egg passage through the ampullary-isthmic junction is associated with a temporary reduction in the activity of egg retaining mechanisms. The retaining mechanisms normally present at the AIJ at the time of ovulation are critically diminished for a period of about $16 \mathrm{~h}$ beginning as early as $36 \mathrm{~h}$ after the injection of HCG, in some animals, or as late as $56 \mathrm{~h}$ in others. During this period, transport from the fimbria to the proximal isthmus is greatly facilitated since ovum surrogates injected $50 \mathrm{~h}$ after HCG had reached the proximal third of the oviduct $8 \mathrm{~h}$ later, although eggs normally take $36 \mathrm{~h}$ to traverse this length of the tube (Pauerstein et al., 1974).

In addition, since most surrogates injected at $50 \mathrm{~h}$ were recovered from the proximal third of the oviduct $8 \mathrm{~h}$ as well as $24 \mathrm{~h}$ later, it follows that retaining mechanisms are also present close to the uterotubal junction, i.e. there are apparently two separate regions where egg retaining mechanisms are present. Furthermore, it appears that one or other of these mechanisms is active at all times. This concept is supported by the fact that resumption of retaining activity at the AIJ precedes the passage of ova into the uterus and is completed, in most animals, by $72 \mathrm{~h}$ after HCG.

The suggested temporal and regional changes in oviductal activity should be taken into consideration in future work concerning the mechanisms underlying ovum transport and retention.

The technical assistance of Mrs Elizabeth Nuñez is gratefully acknowledged. This work was undertaken as part of the Contraceptive Development Research Program sponsored and co-ordinated by the International Committee for Contraception Research of The Population Council, New York. 


\section{References}

ALDEN, R.H. (1942) The oviduct and egg transport in the albino rat. Anat. Rec. 84, 137-170.

Croxatto, H.B., Vogel, C. \& Vásquez, J. (1973) Transport of microspheres in the genital tract of the female rabbit. J. Reprod. Fert. 33, 337-341.

Greenwald, G.S. (1961) Study of the transport of ova through the rabbit oviduct. Fert. Steril. 12, 80-95.

HARPER, M.J.K., BenNetT, J.P., Boursnell, J.C. \& Rowson, L.E.A. (1960) An autoradiographic method for the study of egg transport in the rabbit fallopian tube. J. Reprod. Fert. 1, 249-267.
HUMPHREY, K.W. (1968) Observations on transport of ova in the oviduct of the mouse. J. Endocr. 40, 267-273.

Pauerstein, C.J., Anderson, V., Chatkoff, M.L. \& Hodgson, B.J. (1974) Effect of estrogen and progesterone on the time-course of tubal ovum transport in rabbits. Am. J. Obstet. Gynec. 120, 299-308.

Pauerstein, C.J., Hodgson, B.J., Young, R.J., Chatkofr, M.L. \& Eddy, C.A. (1975) Use of radioactive microspheres for studies of tubal ovum transport. Am. J. Obstet. Gynec. 122, 655-662.

Received 17 August 1976 